\title{
Preventive Maintenance of Mining Equipment Based on Identification of Its Actual Technical State
}

\author{
Vladimir Kovalev, Boris Gerike, Aleksey Khoreshok, Pavel Gerike \\ T.f. Gorbachev Kuzbass State Technical University, Mining Institute, 650099, \\ Kemerovo, Russia
}

\begin{abstract}
The article treats new approach to technical maintenance of open pit excavators based on identification of technical state by functional diagnostics methods. It shows that applied diagnostics methods practically give full picture of actual state of diagnosable equipment which allows to estimate residual work capacity resource.
\end{abstract}

Key words: open pit excavators, technical state, diagnostics, residual work capacity resource.

\section{Introduction}

Nowadays system of scheduled preventive maintenance of equipment is used in open pits of Kuzbass. The main task of the system is to provide work capacity of equipment during preset time and at minimum labour and material asset costs. The present system is based on planned replacement of worn-out parts. The time for parts replacement is calculated on the bases of forecasted parts wear rate. Progressive (wear-out) failures are the most typical failures for rotating equipment.

Maintenance frequency is fixed according to lifetime of group of parts. At the same time, lifetime of each part is close to average lifetime and it can be used to fix the frequency of maintenance of mechanism and machine. The possibility of grouping of working lives of parts according to average values for each group is the main requirement of maintainability of mechanism and machine. In all cases it's important for frequency of repairs, i.e. working lives of parts to be divisible to each other. Frequency of repairs of excavators is set in such a way that parts with emergency phase of wear (at frequency bigger than the lifetime of a group of parts) don't work in mechanisms and parts whose work capacity resource is not completely used (at frequency smaller than average lifetime of group of parts) are not replaced during repair.

There is no theoretically justified decision of given problems in the system of technical maintenance of excavators yet. This creates great choice of recommendations on repair cycle structure formation and setting of different inter repair time for the same machine. For example, according to manual No. 2341IE NKMZ(№2341ИЭ HКM3) for excavator ESH 10/70A (ЭШ $10 / 70 \mathrm{~A}$ )it is recommended to carry out technical maintenance No. 1-5 with frequency: shift, decade, month, three and six monthes.Leningrad office of the State Institute of design of mine construction of coal industry (Ленгипрошахт) recommends to carry out repair inspection, maintenance and capital repairs according to frequency 500, 5000, 12000, 24000 machine-hours. Research Institute of Open-Cast Mining (НИИОГР) suggests plan repair works depending on volumes of processed run of mine taking into account a number of coefficients considering operation conditions of excavators. 
Each normative document establishes rigidly regulated amounts of work during excavator repairs regardless of its technical condition; volumes of repair work increase as repair complexity. For example, at average repair it is necessary to carry out extra works of annual and monthly repairs. Irrespective of operating conditions of parts and assembly units repairs are planned according to one of the criteria - calendar (or machine) operating time or processed run of mine.

All this leads to:

- under exploitation of resource of separate parts, units and assembly units of excavators;

- performance of increased volume of dismantling and assembling works which don't correspond to technical condition of mechanisms and devices, and at the same time, to increase the probability of fast wear of parts caused by wear-in because of frequent dismantling and assembling;

- considerable time of repair ofexcavators $\quad(20-25 \%$ of calendar time fund).

The system of scheduled preventive maintenance in many cases can be used as basis for the service of simple cars and mechanisms, but its application for the main equipment without reserve is inexpedient. Therefore further development of maintenance system should be provided: the establishment of differentiated criteria of assessment of parts resource, assembly units and mechanisms of excavators considering specific conditions of their work; purpose of concrete terms and amounts of work at repairs of excavators depending on actual technical condition of its parts, assembly units and mechanisms.

\section{Work description}

The main idea of the equipment maintenance repair system according to actual technical condition consists in elimination of equipment failures at the stage of their origin ${ }^{[1]}$. It becomes possible with the methods of identification of equipment technical condition according to its operational characteristics, allowing reveal available and developing fault for rational planning of optimal terms of repair work performance.

Technical base of equipment maintenance and repair according to actual technical condition is based on the fact that there is the interaction between possible technical failures of unit and diagnostic parameters which are possible to be controlled. Diagnostic signs of faults may include vibration parameters, technological and regime parameters (loading, temperature, current strength, etc.), admixtures in grease, etc.

Therefore, carrying out monitoring of various parameters characterizing the work of equipment, it is possible to find in time change of technical condition of equipment and to perform maintenance only when there is a real possibility that parameters of equipment go beyond unacceptable limits, that respectively signals about impossibility of further work of object of control.

Maintenance according to the actual technical condition has a number of advantages in comparison with the system of scheduled preventive repairs:

availability of constant information on condition of the equipment under monitoring (possibility of determination of 'problem' and 'normal'units), allows to plan and carry out maintenance and repair without long and often useless stop, practically to exclude equipment crashes. It is possible to increase productive efficiency by means of introduction of system of 
maintenance according to actual technical condition;

- forecasting and planning of volumes of maintenance and repair of 'problem' equipment, maintenance cost reduction due to minimization of useless repair (increase of inter repair interval) of 'normal' equipment. As a result of performance of monitoring of technical condition of units and their maintenance according to actual technical condition offscheduled amount of works caused by emergency situations, usually makes up less than $5 \%$ of total amount of works, and equipment downtime makes up no more than $3 \%$ of time spent for maintenance. It is determined that typical expenses on repair in case of equipment failures exceed repair cost at timely detected defect on average by 10 times ${ }^{[2]}$;

- $\quad$ ensuring efficiency of repair due to post-repair inspection. Experience shows that approximately from 2 to $10 \%$ of new parts have manufacturing defects which can lead to fast failure of replaced part and equipment failure, and also to cause damage of other normally functioning mates. The defective part or broken assembly technology can be found while testing after repair ${ }^{[3]}$;

- effective planning of distribution of maintenance staff, spare parts, tool, etc.;

- possibility of reduction of standby equipment;

- improvement of labour protection and elimination of violations of ecological requirements. Performance of repair works in extraordinary situation of sudden failure and danger of unplanned production suspension leads to the increase of traumatism ${ }^{[4]}$;

- efficiency of negotiations with suppliers of equipment concerning its warranty and post-warranty repair, restoration or replacement. Registered diagnostic parameters are objective data at solution of controversial questions on reasons of mechanism breakdown.

The idea of equipment maintenance according to actual technical condition consists in providing maximum possible inter repair period of equipment operation due to the use of modern technologies of detection and suppression of sources of failures ${ }^{[3]}$.

This system is based on:

- identification and elimination of sources of repeating problems leading to reduction of inter repair interval of equipment maintenance;

- elimination or considerable decrease in factors negatively influencing inter repair interval or equipment lifetime;

- identification of condition of new or restored equipment in order to control signs of defects reducing inter repair interval;

- increase of inter repair interval and equipment lifetime due to carrying out assembling, adjustment and repair works in strict accordance with technical requirements and regulations.

Nondestructive control methods applied in technical diagnosing of bucket excavators are subdivided into 2 main groups:

1. diagnostic (functional) nondestructive control methods: 
- $\quad$ thermal control (TC);

- $\quad$ vibro diagnostic control (VD);

- $\quad$ acoustic emission control (AE).

2. defectoscopy nondestructive control methods:

- visual and measuring control (VMC);

- $\quad$ capillary control (CC);

- $\quad$ ultrasonic control (USC);

- $\quad$ magnetic control (MC).

All types of control and diagnostics should be carried out with the use of standard measuring tools meeting the requirements of the State system of ensuring unity of measurements, and also with use of rules of statistical data processing. To exclude the possibility of operation of parts and units with unacceptable defects suspicious places are checked not less than three times.

We consider in more detail control methods applied at expert inspection of bucket open pit excavators.

When examining industrial safety of open pit excavators visual and measuring control (VMC) method is applied. The purpose of this method is to identify constructive changes in working equipment, rotary platform, main frame, body, etc. (form, surface defects in material and part joints, formed cracks, corrosion and erosive damages, deformations, weakening of joints, etc.) which influence or can influence the safety of operation of excavator ${ }^{[5]}$.

One of dangerous defects detected by VMC are faulty fusions in weld roots, incomplete filling of edge preparations. The main danger of this defect consists in decrease of strength of welded connection, formation of additional concentrators of tension which under unfavourable conditions evolves in main cracks. The deeper is faulty fusion, the higher is the growth rate of main crack.

In parallel with visual and measuring control diagnostic control of excavator equipment can be carried out.
Thermal control (TC) is oriented to assess thermal condition of electric equipment and current-carrying parts depending on conditions of their work and design. It can be carried out according to rated reheat temperatures (temperature rises), excess temperature, defect coefficient, dynamics of temperature change with time, with the change of loading, etc.

At thermal control comparison of results of temperature measurements within phase, between phases, with wittingly operable sites, etc. is carried out. Thermographs with spectral range 8-12 $\mu \mathrm{m}$ and resolution not less than $0,1^{\circ} \mathrm{C}$ are used to perform TC.

However, the most informative parameter carrying maximum information on condition of assembly of working machine or unit, is mechanical oscillations (vibrations) - elastic waves diffusive in continuum. Information on change of condition of object can be received immediately. These features predetermined the application of vibration method of diagnostics and control (VD) as the main one.

Measurement of vibro acoustic characteristics of bearing supports of mechanisms allows to detect such defects and damages as imbalance and misalignment of shafts; damages of sliding and rolling bearings; damages of gearings inchange-wheel gears; damages of couplings; damages of electric machines ${ }^{[3]}$.

As is well known, the most effective method of vibration diagnostics is continuous monitoring allowing receive in proper time exact and reliable information about equipment condition. This task seems to be especially urgent for fleet of bucket open pit excavators. When signs of cracks in supporting irons or welded seams of excavator are detected additional inspection by means of one of defectoscopy nondestructive control methods is used: 
- $\quad$ ultrasonic control (USC);

- dye penetrant inspection (capillary control).

Ultrasonic control based on the capacity of ultrasonic vibrations to diffuse deeply in solid substances without noticeable weakening and to be reflected from interface of two substances, is the most reliable and simple method of defectoscopy of critical parts and welded connections of excavators. They distinguish 5 USC methods: shadow, resonant, impedance, free vibrations and echo method. The application of ultrasonic phased array is considered to be state-of-the-art technology.

The main advantage of ultrasonic phased arrays is the possibility of program formation of polar pattern of ultrasonic unit, including focusing, insertion point and angle. It allows to realize all control schemes used in multielement systems with linear scan, applying the same PEP. So, for example, the defectoscope X-32 ${ }^{[6]}$ has obvious interface, it is handy in work, and numerous functions realized in it, facilitate and optimize control process:

- presence of 32 active elements provides high spatial resolution that allows to receive distributions and exact defect sizes;

- formation of ultrasonic beams under more than 2000 angles to receive maximum control and resolution area;

- $\quad$ use of up to 128 elements allows to carry out multiplexing (linear scanning);

- presence of modes of onedimensional echography (Ascanning), two-dimensional echography (B-scanning), linear (L) and sector (S) scanning in real time with analysis of images in all modes of scanning.

Dye penetrant inspection is to determine locations of surface defects with exposed cavity, their directions, extent, nature of development both inbase and built-up metal of welded connections ${ }^{[7]}$.

Acoustic emission control (AE-control) of basic bearing elements of excavator body is aimed at detecting of developing defects in welded seams formed over long period of operation at the expense of accumulation of tensions as a result of cyclic operation mode.

The following elements of construction are to be controlled: boom, top slopes, front and back braces, cross-beam, frame, support, cathead, air receiver for pneumatic system.

Welded seams of basic bearing elements of excavator construction are concentrators of tension, and operational defects in them are caused by various defects of welding, have casual character, both according to the time of origin and location ${ }^{[8]}$.

Acoustic emission control used in real time for operating equipment allows reveal potentially dangerous places in construction, moment of formation of developing defect and its coordinates practically without interruption of work, to say unambiguously about defect development.

Examination of area of hyperactivity detected that cluster of area of damage found itself in swing joint of vertical support of circular section and bottom flange beam. Examination of detected area shows increase in diameter of pin bore in lug, and traces from blows and friction on finger itself.

Thus, by results of acoustic emission control of basic elements of excavator body operational defects the identification of which by traditional control methods demands both considerable financial and labour expenses can be detected. At the same time, it is often difficult to give answer about the need and expediency of repair work performance. 


\section{Conclusion}

Nowadays, the reduction of specific operational costs on maintenance at open pit equipment operation is one of the main reserves of production efficiency increase. Modern methods of technical diagnosing, equipment for their realization and software allow receive with very high level of reliability the opinion about actual technical condition of open pit excavators.

\section{References}

[1] Diagnosing of technical equipment of hazardous production facilities/ A.N. Smirnov, B.L. Gerike, V.V. Muraviev//Novosibirsk. - Nauka. - 2003. $-320 \mathrm{p}$.

[2] Shirman A.R., Solovyov A.B. Practical vibration diagnostics and monitoring of condition of mechanical equipment. M. 1996. - 208 p.

[3] Diagnostics of mining machinery and equipment: Tutorial/B.L. Gerike, P.B. Gerike, V.S. Kvaginidze, G.I. Kozovoi, A.A. Khoreshok//M.: IPO 'U Nikitskihvorot', 2012. - 400 p.

[4] Kvaginidze V.S., Zaripova S.N. Statistical analysis and forecasting of industrial injuries at coal-mining enterprises/ GIAB. Appendix 'Yakutia'. Publisher MSMU. - 2006. - \#2. - P. 221232.

[5] RD 03-606-03. Instruction on visual and measuring control, approved by the resolution of GGTN of the Russian Federation from 11.06.03, \#92.

[6] Innovative ways of operability assurance of mining machinery on the basis of monitoring of their technical condition/ B.L. Gerike, I.L. Abramov, P.B. Gerike// Kuzbass: Collection of scientific papers. Fascicle of Mining information and analytical bulletin. 2008. - \#7. - P. 228-240.

[7] Kalinichin N.P., Kuleshova G.P. Nondestructive control. Capillary method/M. - publisherIntroscopy Research Institute. - 2002. - 101 p.

[8] Assessment of technical condition of supporting irons of walking excavators according to parameters of acoustic emission signal/ B.L. Gerike, S.I. Protasov, A.V. Menchugin, P.V. Buyankin// Mining equipment and electromechanics. - 2009. - \#5. - P. 2530. 